\title{
CONVERGÊNCIA E INTEGRAÇÃO DE TECNOLOGIAS CRIATIVAS EM AMBIENTES VIRTUAIS
}

\author{
CONVERGENCE AND TECHNOLOGY INTEGRATION OF CREATIVE IN \\ VIRTUAL ENVIRONMENTS
}

\section{CONVERGENCIA Y INTEGRACIÓN DE TECNOLOGÍA LA CREATIVIDAD EN ENTORNOS VIRTUALES}

\section{Ilse Abegg ${ }^{1}$ \\ Fábio da Purificação de Bastos ${ }^{2}$}

\begin{abstract}
RESUMO: As Tecnologias de Informação e Comunicação (TIC) possuem uma grande relevância na vida dos indivíduos na sociedade contemporânea. Isso porque estão inseridas em vários contextos do dia a dia, inclusive na educação. Nosso objetivo é trazer contribuições e resultados de pesquisas realizadas no escopo da escolaridade, na implementação de proposta pedagógica na perspectiva da convergência e integração. Convergência entre modalidades educacionais mediadas por Ambiente Virtual de Ensino-Aprendizagem (AVEA) e integração das TICs para o desenvolvimento de produção colaborativa. Destacamos as tecnologias criativas como ferramentas para a organização das atividades de estudo. A pesquisa-ação desenvolvida teve o foco na referida integração e convergências das tecnologias criativas, centrando-se nas ferramentas wiki e glossário do Moodle, para promover a colaboração em rede. Como resultados, apontamos contribuições inovadoras no âmbito do planejamento, monitoramento e avaliação em rede das ações docentes e discentes mediadas tecnologicamente. Além disso, sistematizamos a ampliação e o aprimoramento do desenvolvimento da fluência tecnológica de todos os envolvidos.
\end{abstract}

PALAVRAS-CHAVE: Ambiente Virtual de Aprendizagem. Tecnologia Educacional. Disseminação da Tecnologia Educacional.

\begin{abstract}
Information and Communication Technologies (ICT) have a great importance in the lives of individuals in contemporary society. This is because they are inserted in various contexts of everyday life, including education. We aim to bring contributions and research findings in education, implementation of the pedagogical proposal in the context of convergence and integration. Convergence between educational modalities mediated Virtual Environment of Teaching and Learning (VETL) and integration of ICT for the development of collaborative production. We highlight the creative technologies as tools for the organization of study activities. The developed action research had focused on that integration and convergence of creative technologies, especially in wiki tools and glossary of Moodle, to promote collaborative networking. As a result, we point innovative contributions in the planning, monitoring and evaluation network of technologically mediated actions of teachers and students. In addition, we systematized the expansion and improvement of the development of technological fluency of all involved.
\end{abstract}

KEYWORDS: Virtual Learning Environment. Educational technology. Dissemination of Educational Technology.

RESUMEN: Tecnologías de la Comunicación y la información (TIC) tienen una gran importancia en la vida de los individuos en la sociedad contemporánea. Esto se debe a que se insertan en los diversos contextos de la vida cotidiana,

\footnotetext{
${ }^{1}$ Doutora em Informática na Educação pela Universidade Federal do Rio Grande do Sul - UFRGS, Porto Alegre, RS Brasil. Professora adjunta no Departamento de Metodologia do Ensino, Centro de Educação da Universidade Federal de Santa Maria - UFSM, Santa Maria, RS, Brasil. E-mail: ilse.abegg@ufsm.br.

${ }^{2}$ Doutor em Educação pela Universidade de São Paulo - USP. Professor titular do Departamento de Metodologia do Ensino, Centro de Educação da Universidade Federal de Santa Maria - UFSM, Santa Maria, RS, Brasil. E-mail: fabio@ufsm.br.
}

Recebido em: 26/05/2015 - Aprovado em: 03/12/2015. 
como la educación. Nuestro objetivo es traer aportes y resultados de la investigación en la educación, la implementación de la propuesta pedagógica en el contexto de la convergencia y la integración. La convergencia entre modalidades educativas mediada Entorno Virtual de Enseñanza y Aprendizaje (VETL) y la integración de las TIC para el desarrollo de la producción colaborativa. Destacamos las tecnologías creativas como herramientas para la organización de actividades de estudio. La investigación-acción desarrollada se había centrado en que la integración y convergencia de las tecnologías creativas, especialmente en herramientas wiki y glosario de Moodle, para promover la creación de redes de colaboración. Como resultado de ello, señalamos contribuciones innovadoras en la planificación, seguimiento y evaluación en línea de las acciones tecnológicamente mediadas de profesores y estudiantes. Además, hemos sistematizado la ampliación y mejora del desarrollo de la fluidez tecnológica de todos los involucrados.

PALABRAS CLAVE: Entorno Virtual de Aprendizaje. Tecnología educacional. Difusión de Tecnología. Educativa.

\section{INTRODUÇÃO}

Na sociedade contemporânea, permeada pelas Tecnologias da Informação e Comunicação (TIC), as mesmas têm sido relevantes para a inovação na educação. Pode-se entendê-las como um componente inovador capaz de estabelecer novas dinâmicas nas práticas pedagógicas tradicionais e transmissoras. Esse contexto tecnológico disponibiliza as chamadas "tecnologias criativas" que possibilitam, além da ampliação dos processos de interação e comunicação, aprimorar o ensinoaprendizagem (HACKBARTH, 1996). Consideramos que tecnologias criativas são "os conjuntos de técnicas, práticas e modos de pensamento envolvido na externalização de ideias dentro de domínios específicos em que a externalização ocorre de forma inteligente (na terminologia de Bergson), ou seja: criativamente" (LIBORIUSSEN, 2012, p. 31, grifos em negrito nossos).

Trazemos contribuições ancoradas em resultados de pesquisa-ação realizada na escolaridade superior, visando sempre a implementação de propostas pedagógicas na perspectiva da convergência e integração. Convergência esta entre modalidades educacionais mediadas por Ambiente Virtual de Ensino-Aprendizagem (AVEA) e integração das TIC para o desenvolvimento de produção colaborativa. No campo da prática, implementamos ações escolares mediadas por AVEA para o desenvolvimento da produção colaborativa e sistematização dos processos vivenciados, tendo as tecnologias criativas como ferramentas para organização das atividades de estudo.

A relevância deste trabalho está na incorporação das tecnologias criativas, na escolaridade mediada tecnologicamente, assim como no desenvolvimento da fluência tecnológica ${ }^{3}$ dos envolvidos. Nosso intuito é possibilitar a motivação, colaboração, criatividade e interação dialógicoproblematizadora entre professor-estudante e estudante-estudante. Além disso, propiciar inovações no processo de ensino-aprendizagem, contribuindo para os desdobramentos das práticas pedagógicas em rede.

\footnotetext{
${ }^{3} \mathrm{~A}$ noção de fluência é a "capacidade de reformular conhecimentos, expressar-se criativa e apropriadamente, bem como produzir e gerar informações, em vez de meramente compreendê-las" (TAKAHASHI, 2000, p.45).
} 


\section{CONVERGÊNCIA DAS TECNOLOGIAS CRIATIVAS NA ESCOLARIDADE}

Já é de algum tempo que se aponta para a necessidade de replanejar as práticas escolares a partir da integração das TIC, principalmente as tecnologias criativas. Por isso, nossos estudos voltam-se para a temática da integração, nas atividades escolares, via ferramentas de produção colaborativas em rede, especialmente as dos AVEA, e no nosso caso em particular, o Moodle. Tal proposição deve-se ao fato de que o AVEA é um espaço virtual educativo hipermidiático. Nele temos ferramentas de recursos e atividades potencializadoras de práticas educativas integradoras e convergentes. Além disso, integra os processos de comunicação e interação e proporciona a produção colaborativa do conhecimento escolar, via tecnologias criativas, como as ferramentas de atividades wiki e glossário.

A integração e convergência via tecnologias criativas no processo de ensino-aprendizagem torna-se hoje um requisito necessário para um maior envolvimento dos estudantes nas atividades escolares. Isso porque a realidade vivida atualmente está permeada pelas tecnologias criativas nos diversos aparatos tecnológicos que são utilizados para se comunicar, pesquisar, trabalhar e, inclusive, estudar.

Cysneiros (2000) sinaliza que o computador pode conter várias tecnologias educacionais, funcionando em rede ou não. Torna-se uma tecnologia educacional quando passa a mediar um conjunto de ações no escopo do ensinar e aprender, envolvendo interações entre quem ensina e aprende. Todas as novas possibilidades inauguradas pelas TIC potencializam a criatividade, inclusive nas formas de customização e uso das mesmas. Como, por exemplo, o uso da hipermídia, em que a convergência de tecnologias digitais e virtuais aumenta a possibilidade do movimento cognoscente.

Por outro lado, o aumento na capacidade de armazenar conteúdos escolares em banco de dados dos ambientes virtuais de ensino-aprendizagem pode mobilizar a reutilização dos mesmos em tempos didáticos subsequentes. Consequentemente, melhora a organização e retroalimentação constante dos conteúdos, em especial no contexto das redes, visto que ferramentas de interatividade e interação têm evoluído, inclusive, nas suas interfaces gráficas.

O que está no horizonte não é apenas a mediação pelas tecnologias criativas, mas sua convergência para a criação colaborativa do conhecimento, que precisa, além de integrar as mesmas no conjunto das práticas escolares, colaborar com a construção do novo cenário educativo-criativo.

É exatamente isso que os estudantes e professores precisam fazer na contemporaneidade! Inclusive quando estão realizando tarefas escolares, muitas vezes que poderiam ser operacionalizadas em rede nos ambientes virtuais de ensino-aprendizagem. Portanto, a convergência das tecnologias criativas no desenvolvimento das atividades escolares pode se tornar uma alternativa para ampliar a colaboração e o interesse dos estudantes e professores.

Quando o ambiente virtual de ensino-aprendizagem opera com recursos e atividades hipermídia, disponibiliza conteúdos pela convergência de mídias. Em outras palavras, opera com 
recursos tecnológicos das redes eletrônicas de forma criativa, reduzindo problemas de interfaces e de funcionamento isolado de aplicativos. Convergência neste sentido, é um conceito que consegue delimitar transformações tecnológicas, com potencial de inovar e mudar nos campos cultural e socioeducacional.

Embora muitos autores, em meados da década de 1990, afirmassem que a internet teria se transformado no principal meio de convergência de todas as tecnologias de informação e da comunicação, a esfera do conhecimento educacional ainda permanecia distante, talvez por aquelas serem digitais e síncronas (online). Percebemos uma boa aproximação quando tecnologias criativas, na perspectiva colaborativa, como ambientes virtuais de ensino-aprendizagem livres a abertos, foram se tornando o principal mediador de sistemas de educação aberta.

Zuin (2010) ressalta a cultura da convergência no Plano Nacional da Educação (PNE) 2011$2020^{4}$, destacando que a tecnologia ocupa cada vez mais posição-chave na sociedade atual, de modo que ela não mais pode ser definida como uma somatória de novas técnicas operacionais, mas sim como um modus vivendi. Convergência midiática que acarreta mais do que uma simples visão de mudança tecnológica, em especial na educação, quando altera as relações entre os desenvolvimentos tecnológico e industrial, até pouco tempo atrás antagônicos e contrapostos.

Com os avanços tecnológicos da atualidade - por exemplo, os dispositivos móveis (smartphones, tablets entre outros) -, a convergência, na perspectiva apontada, influencia os modos de produção das pessoas (o que inclui estudantes e professores), quando se comunicam e participam da vida em sociedade. Consequentemente, temos uma maior qualidade participativa nos processos de produção colaborativa, possibilitando o desenvolvimento da criatividade ao compartilharem as mesmas nas formas de fotos, vídeos, de produção própria, na rede (GANGUIN; HOBLITZ, 2012). Essa qualidade participativa é estimada em função do conteúdo da produção colaborativa.

Nesse contexto, aqueles que têm boa fluência tecnológica dispõem também da "opção de produzir conteúdo e compartilhá-lo na Internet, o que significa que 'co-criação' é uma característicachave da comunicação interativa" (KLIMMT; VORDERER; RITTERFELD, 2007: 171, In.: GANGUIN; HOBLITZ, 2012). Isso em boa parte, é propiciado pelas tecnologias criativas, que possibilitam a comunicação interativa e colaboração. Além disso, permitem a participação efetiva no processo de produção, tornando o participante prosumer 5 .

Tal perspectiva educacional precisa estar presente também no processo de escolaridade, pois, segundo Freire (1997), é preciso que o estudante vá assumindo o papel de sujeito da produção, reconhecendo-se como arquiteto de sua própria prática cognoscitiva. Afinal, "o ensino de conteúdos demanda que quem se acha na condição de aprendiz, vá assumindo a autoria também do conhecimento do objeto" (FREIRE, 1997, p. 40, grifos nossos).

${ }^{4}$ O Plano Nacional de Educação (PNE) com previsão para 2011-2020 acabou sendo finalizado e aprovado para 20142024.

${ }^{5}$ http://pt.wikipedia.org/wiki/Prosumer 
Assim, a criação colaborativa de conteúdo, potencializada pelas tecnologias criativas em rede, viabiliza aos estudantes e professores a possibilidade de Ser Mais na perspectiva da educação como prática da liberdade (FREIRE, 1997). Dessa forma, a escolarização deixa de ser uma ação de consumo de conteúdos culturais, passando a ser um espaço de produção colaborativa e compartilhamento.

É essencial termos em mente que, mediados pelas tecnologias criativas, podemos compartilhar com o intuito de criar. Isso coloca a criatividade no escopo da produção em rede, mudando a participação, transformando-a em colaborativa. Colaboração em rede, nas comunidades da internet.

\begin{abstract}
As novas tecnologias criativas estão a criar o terreno para o próximo grande movimento cultural dando voz aos utilizadores para expressar sentimentos, ideias e visões, transformando e dando forma a tudo o que a imaginação pode gerar. Acreditamos que cada vez mais os utilizadores finais irão projetar, construir e partilhar os seus próprios mundos, e em larga medida contribuir para os diversos futuros tecnológicos (ZAGALO; BRANCO, 2012, p. 5, grifos nossos).
\end{abstract}

Consideramos que essas tecnologias criativas, por serem tomadas apenas no conjunto das técnicas, práticas e modos de pensamentos, são utilizadas na comunicação de ideias e atividades criativas. Por essa concepção, vemos que não podemos compreender tecnologias criativas em domínio algum que não seja o da prática, ou seja, elas não mediam apenas a prática, mas são a própria prática tecnológica. Por isso, a necessidade da fluência tecnológica, também, fazer parte do processo de escolarização.

No contexto de convergência, portanto, ensino-aprendizagem mediado por AVEA torna-se tecnologia criativa quando externaliza uma organização didático-metodológica em rede 'de forma inteligente' e em sintonia com o desenvolvimento tecnológico atual. Dito de outra forma, torna-se uma plataforma de trabalho colaborativo em rede para o desenvolvimento de atividades de estudos, externalizando um ensino-aprendizagem criativo, por meio de um conjunto de ferramentas de recursos e atividades.

Dentre as ferramentas de atividades disponíveis no Moodle com potencial tecnológicocriativo, destacamos a wiki e glossário, pela possibilidade de ensejar práticas colaborativas. Assim, quando mediam práticas colaborativas em rede, as conceituamos como tecnologias criativas. Isso por causa de seu caráter hipermidiático e por serem interativas e gerar interação dialógicoproblematizadora no escopo da produção colaborativa.

Práticas escolares mediadas por tecnologias criativas, obrigatoriamente interativas, geram movimentos colaborativos. Ao propormos atividades de estudos colaborativas, mediadas por tecnologias criativas, na prática dialógico-problematizadora, centramos o ensino-aprendizagem colaborativo na esfera da liberdade. Assim, favorecendo a colaboração, cria-se a cultura do compartilhamento e produção em pares.

Por fim, cabe destacar que nossas ações na perspectiva investigativa ativa, coloca o ensinoaprendizagem no escopo da resolução de problemas. Problematização caracterizada pela conduta 
dialógica e mediada por ferramentas de produção colaborativa do conhecimento, na interação entre estudantes e professores.

\section{CONCEPÇÃO TEÓRICO-METODOLÓGICA DE PESQUISA E IMPLEMENTAÇÃO DAS AÇÕES COMO RESULTADOS}

Nossos trabalhos acadêmicos estão ancorados nos princípios da pesquisa-ação, uma vez que seus referenciais teórico-metodológicos permitem que a prática ocorra de forma dialógica, colaborativa e na perspectiva da liberdade. A pesquisa-ação, na perspectiva emancipatória, tem interfaces com a educação como prática da liberdade. Ambas são caracterizadas como processos de ação-reflexão-ação na esfera da conscientização. Na prática, ocorrem ao longo das seguintes etapas: diagnóstico inicial (investigação temática), planejamento (redução temática), ação (com registro e observação), avaliação (deliberativa voltada para o replanejamento), formando uma espiral de círculos de cultura, em um movimento de retrospecção e prospecção (dinâmica codificaçãodescodificação) (CARR; KEMMIS, 1986; FREIRE, 2014).

$\mathrm{Na}$ etapa de diagnóstico inicial, investigam-se as ações que queremos mudar como problemas para resolver, tornando-as situações-problema. Isso é identificado pela leitura efetuada no local da prática. Em nosso caso, foi realizado um diagnóstico visando conhecer a fluência tecnológica do (a)s estudantes e suas necessidades culturais, utilizando a ferramenta de atividade Pesquisa de Avaliação do Moodle. A partir das análises, foi possível fazer um diagnóstico inicial e guiar o processo de planejamento e implementação com ações criativas, visto serem mediadas por tecnologias educacionais em rede, para resolver os problemas de fluência. Nesta etapa inicial, o que se pretende investigar do ponto de vista escolar, não são os sujeitos apenas, mas seus pensamentoslinguagens em relação à realidade escolar, assim como os níveis de percepção dela, as suas visões de mundo e, principalmente, suas ações escolares (ABEGG; BASTOS, 2005).

No planejamento, pensado como ação prospectiva, baseado nos resultados do diagnóstico inicial, ocorreu o primeiro movimento retrospecção-prospecção, projetando-se ações para implementação. Assim, iniciamos a organização da navegação interativa no AVEA, com o intuito de guiar as ações dos estudantes (por exemplo, registros individuais de login e senha; atualização de perfil; comunicação com os participantes e configuração da página inicial de forma personalizada), para posterior realização das atividades de estudo mediadas pelas tecnologias criativas wiki e glossário do Moodle. As referidas atividades de estudo foram sendo planejadas de forma criativa nas ferramentas de atividade wiki e glossário do AVEA, tendo como foco investigativo a fluência tecnológica nas mesmas, visto a criatividade em questão ser diretamente dependente dessas práticas mediadas tecnologicamente.

$\mathrm{Na}$ ação executamos as ações criativas, por meio de um roteiro com um sequenciamento didático das mesmas. Também fizemos as primeiras autorreflexões (baseadas nos registros e observações) na prática vivida, fazendo emergir os sentidos da apreensão dos significados construídos e em construção de cada um dos participantes. A produção colaborativa nas ferramentas wiki e glossário tem um caráter coletivo, embora seja composta por ações individuais. Nesse 
contexto, o trabalho em equipe é estratégico e fundamental para que se desenvolva de forma colaborativa e criativa no AVEA.

Na avaliação, apresentamos ciclo após ciclo os resultados de investigação das ações contextualizadas organizacionalmente pelo foco investigativo, extraindo elementos úteis para avançar na perspectiva da resolução do problema. Logo, a cada ação realizada, replanejamos as próximas ações criativas, tensionando a prática mediada pelas ferramentas wiki e glossário do Moodle nos escopos de pesquisa (teórica) e investigação (prática escolar).

Nos espaços de participação, as atividades de estudo foram previamente planejadas com pelo menos dois intuitos: apreender o conteúdo e melhorar a fluência tecnológica. Na figura 1, a seguir, é possível visualizar a área de trabalho de uma das turmas com as ferramentas Glossário e Wiki aliadas às atividades planejadas pela professora da turma:

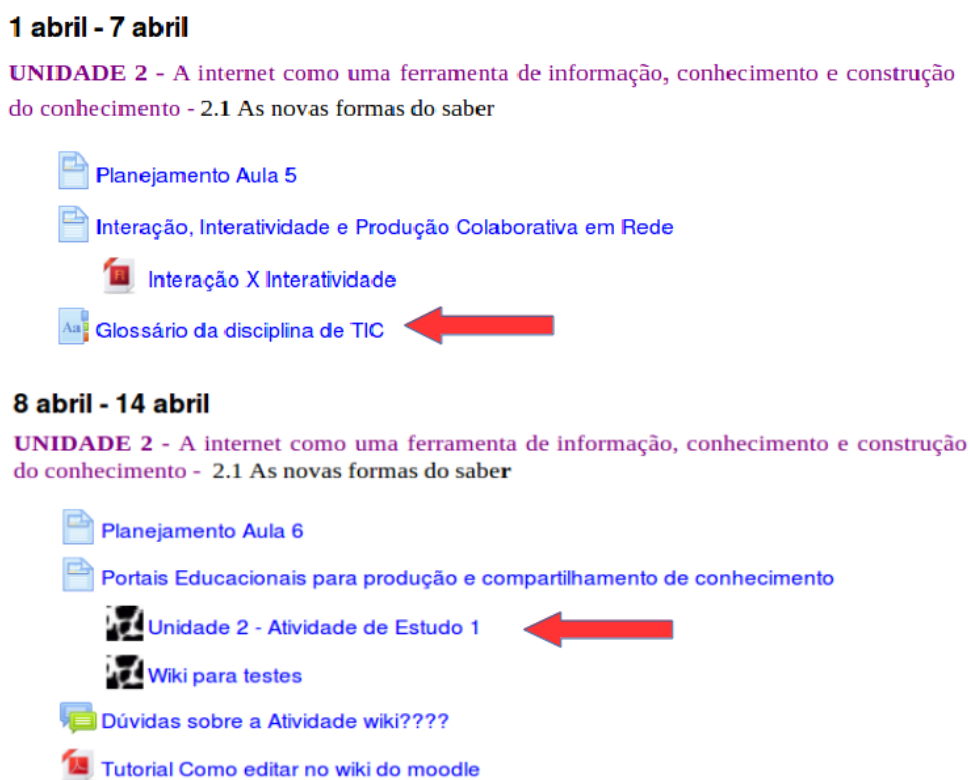

FIGURA 1 - áreas de trabalho no Moodle, com as ferramentas glossário e wiki Fonte: dos autores

Com a disponibilização de tecnologias criativas no Moodle, torna-se possível integrar estudantes e professores de forma mais colaborativa nas ações escolares, uma vez que estas potencializam inovações e desenvolvimento da criatividade.

$\mathrm{Na}$ figura 2, a seguir, exemplifica-se como implementamos as ações didáticas, tendo as tecnologias criativas como ferramenta mediadora das atividades de estudo. A partir da ferramenta wiki do Moodle, foi proposta uma produção de escrita colaborativa com uma turma do curso de formação inicial de professores para educação profissional, no contexto do Programa Especial de Graduação (PEG), ofertado pela instituição dos pesquisadores. A atividade foi planejada previamente pela professora objetivando trabalhar os conteúdos que estavam sendo estudados nas aulas da 
disciplina de Tecnologias da Informação e Comunicação aplicadas à educação, assim como, visando ao desenvolvimento da fluência nas tecnologias criativas:

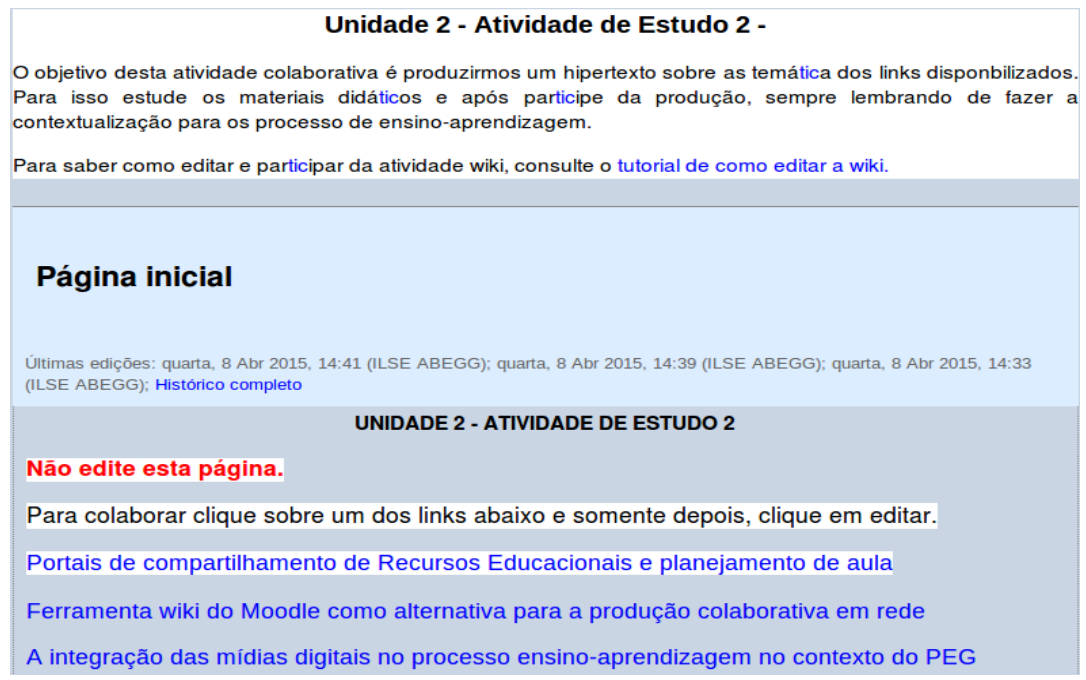

FIGURA 2 - atividade de estudo na ferramenta wiki do Moodle

Fonte: dos autores

A participação nessa atividade de produção colaborativa, utilizando a ferramenta wiki do Moodle, pode ser observada na figura 3, a seguir. Para exemplificar, destaca-se uma parte do histórico das edições, o qual nos mostra a data, hora, quantidade de palavras inseridas ou excluídas por cada um dos participantes. (Os sobrenomes foram suprimidos para preservar a identidade dos mesmos.)

\begin{tabular}{|c|c|c|c|c|}
\hline Data & Hora & & Palavras & Alterado por \\
\hline \multirow[t]{2}{*}{22 abril 2015} & 23:03 & Ver (alteraçōes) & +45 & GERALDO J \\
\hline & $21: 40$ & Ver (alteraçōes) & +44 & LITIÉRRI RA: \\
\hline \multirow[t]{5}{*}{21 abril 2015} & $22: 28$ & Ver (alteraçōes) & & JANAINA OT \\
\hline & $22: 25$ & Ver (alteraçōes) & & JANAINA OT \\
\hline & $22: 24$ & Ver (alteraçōes) & & JANAINA OT \\
\hline & $22: 22$ & Ver (alteraçōes) & +482 & JANAINA OT \\
\hline & $16: 33$ & Ver (alteraçōes) & +64 & CRISTIANE \\
\hline 20 abril 2015 & $19: 50$ & Ver (alteraçōes) & +157 & MARTA ELEP \\
\hline 19 abril 2015 & $22: 43$ & Ver (alteraçōes) & & CRISTIANE \\
\hline 18 abril 2015 & $11: 16$ & Ver (alteraçōes) & +78 & LEONARDO \\
\hline \multirow[t]{2}{*}{15 abril 2015} & $09: 39$ & Ver (alteraçōes) & -1 & NANCI TERE \\
\hline & $09: 32$ & Ver (alteraçōes) & +75 & NANCI TERE \\
\hline \multirow[t]{2}{*}{10 abril 2015} & $13: 54$ & Ver (alteraçōes) & +11 & DIEGO DORI \\
\hline & $13: 50$ & Ver (alteraçōes) & +108 & DIEGO DORI \\
\hline
\end{tabular}

FIGURA 3 - recorte do histórico da produção colaborativa na ferramenta wiki do Moodle Fonte: dos autores 
Além disso, o histórico nos permite ver as alterações produzidas e, inclusive, comparar versões. Pode-se dizer, também, que quanto maior o histórico com alternância de participantes, maior o processo de colaboração na produção.

\section{ANÁLISES E CONCLUSÕES}

Os resultados aqui apresentados são oriundos do movimento investigativo colaborativo, mediado por tecnologias educacionais em rede, sendo, portanto, de natureza tecnológica criativa. Além de trazerem elementos que apontam para a inserção de práticas inovadoras, implementadas com tecnologias criativas em ambiente virtual de ensino-aprendizagem, sinalizam direções para o desenvolvimento da fluência tecnológica no escopo colaborativo.

A disponibilização de espaços virtuais com softwares livres educacionais muda a realidade da produção escolar, permitindo que professores e estudantes realizem suas atividades de forma colaborativa, mediados por tecnologias criativas, otimizadoras do par desenvolvimento-tempo. Investigar ativamente esses processos de mediação em atividades de estudo, na perspectiva das tecnologias criativas em AVEA, torna-se relevante e necessário, inclusive, na esfera do movimento social do software livre que os desenvolve.

Na perspectiva da convergência e integração das tecnologias criativas em ambientes virtuais de ensino-aprendizagem, convém destacar que os wiki e glossário do Moodle, na maioria das vezes, são subutilizados por professores e estudantes. Conforme depoimento dos participantes, muitas vezes ocorre pelo fato da falta de fluência tecnológica. Contraditoriamente, visualizam apenas as limitações tecnológicas nas referidas ferramentas, sem ao menos experimentá-las no contexto real das práticas escolares em rede.

Do trabalho realizado, podemos sinalizar que as atividades wiki e glossário do Moodle configuram-se em tecnologias criativas, exatamente por mediarem práticas escolares colaborativas em rede (LIBORIUSSEN, 2012). Práticas conduzidas por planejamento, também em rede e colaborativo, expressando técnicas, práticas e modos de pensamento que externalizam ideias educacionais em domínios específicos (formação inicial de professores para educação profissional em rede) e isso ocorre de forma inteligente pelas tecnologias educacionais em rede.

\section{REFLEXÕES E PROSPECÇÕES}

Investigar ativamente processos de mediação nas atividades de estudo, convergindo e integrando tecnologias criativas, necessita gerar contribuições e resultados inovadores (desenvolvimentos) no âmbito do planejamento, monitoramento e avaliação das ações docentes e discentes. Se por um lado isso potencializa o desenvolvimento de fluência tecnológica necessária ao mundo do trabalho, por outro, pode se tornar uma alternativa viável-possível para implementar novas funções ferramentais. Dito de outra forma, não podemos almejar desenvolvimentos inovadores em tecnologias educacionais (ferramentas de atividades que mediam a produção escolar colaborativa, como as ferramentas wiki e glossário do Moodle), se estudantes e professores não participarem mais ativamente, de forma criativa, como prosumers, não apenas dos conteúdos científico-tecnológicos escolares, como também e, concomitantemente, das respectivas tecnologias. 
Pesquisas como esta nos fazem perceber que é possível gerar inovações no processo de ensino-aprendizagem, na perspectiva da integração e convergência das tecnologias criativas. Contudo, é necessário nos experimentarmos na produção escolar mediada pelas ferramentas de atividades wiki e glossário do Moodle, que é o que dispomos atualmente no mundo livre e aberto. Isso é viável-possível de produzir no âmbito curricular inovador, colaborativamente em rede com estudantes e professores, na perspectiva da educação como prática da liberdade (FREIRE, 1967). O desenvolvimento de diferentes versões da ferramenta de atividade wiki do moodle é fruto de participação na comunidade do referente aplicativo.

Embora possamos não ter destacado suficientemente neste trabalho, ressaltamos que o resultado principal de pesquisa é a mudança da forma de produção escolar, agora centrada na produção colaborativa em rede. Se por um lado, isso exige trabalhos mais exaustivos e diversos, por outro, nos faz perceber que o desenvolvimento da fluência tecnológica é essencial para o trabalho com tecnologias criativas em ambientes virtuais.

Além disso, os resultados deste trabalho se aproximam cada vez mais da realidade local, empoderando-nos com tecnologias criativas. Isso porque a participação na produção escolar colaborativa nos possibilita o estabelecimento de diversas interações (experimentais) no processo de ensino-aprendizagem em rede.

No contexto educacional atual, ser mediado virtualmente pelo Moodle nos permite ampliar os espaços tradicionais de ensino-aprendizagem, mudando o modo de produção do conhecimento escolar para a perspectiva colaborativa em rede de forma criativa. Isso, além de ampliar o desenvolvimento de interatividade, interação e diálogo-problematizador, potencializa o compartilhamento e colaboração. Por isso, a integração das tecnologias criativas no processo escolar precisa produzir desenvolvimento curricular, com vistas à ampliação do desenvolvimento humano na perspectiva do ser mais.

Nos trabalhos futuros, pretendemos pontuar mais melhorias no processo de ensinoaprendizagem colaborativo na perspectiva da liberdade. Para tanto, otimizaremos a produção escolar mediada pelas ferramentas de atividades wiki e glossário do Moodle, convergindo as tecnologias criativas. Isso porque acreditamos ser possível produzir desenvolvimentos curriculares inovadores, com produção escolar colaborativa (via conhecimentos técnico, prático e emancipatório), perceptível como fluência tecnológica acoplada a tecnologias criativas. 


\section{REFERÊNCIAS}

ABEGG, Ilse; BASTOS, Fábio da Purificação de . Fundamentos para uma prática de ensino-investigativa em Ciências Naturais e suas tecnologias: exemplar de uma experiência em séries iniciais. Revista Electrónica de Enseñanza de las Ciencias, v. 4, n. 3, 2005. Disponível em: 〈http://goo.gl/n1mBRq $\rangle$. Acesso em: 26 mai. 2015. ISSN 1579-1513.

ABEGG, Ilse. Produção colaborativa e diálogo-problematizador mediados pelas tecnologias da informação e comunicação livres. 2009. 183 f. Tese (Doutorado em Informática na Educação). Centro Interdisciplinar de Novas Tecnologias na Educação, Universidade Federal do Rio Grande do Sul, Porto Alegre, RS, 2009. Disponível em: 〈http://goo.gl/5c1BFc〉. Acesso em: 26 mai. 2015.

CARR, Wilfred; KEMMIS, Stephen. Becoming critical: education, knowledge and action research. London: The Falmer Press. 1986.

CYSNEIROS, Paulo G. Novas tecnologias no cotidiano da escola. Reunião Anual da 23. ANPEd. Caxambu, Minas Gerais. set. 2000. Disponível em: < http://goo.gl/bGA7zu $>$. Acesso em: 26 mai. 2015.

FREIRE, Paulo. Educação como prática da liberdade. Rio de Janeiro: Paz e Terra. 1967. Disponível em: 〈http://goo.gl/iRBqsY >. Acesso em: 26 mai. 2015.

FREIRE, Paulo. Pedagogia do oprimido. 17.ed. Rio de Janeiro: Paz e Terra, 1987. Disponível em: 〈http://goo.g1/kDiZ22>. Acesso em: 23 jun. 2014.

GANGUIN, Sonja; HOBLITZ, Anna. Mobile Media - Mobile Creativity? Revista Comunicação e Sociedade, Braga, Portugal, v. 22. 2012. Disponível em: 〈http://goo.gl/ZTqDzW〉. Acesso em: 26 mai. 2015. ISSN 2183-3375.

HACKBARTH, Steven. The educational technology handbook: a comprehensive guide. Educational Techonology Publications, Englewoods Cliffs, New Jersey, USA, 1996.

LIBORIUSSEN, Bjarke. On the Origin Myths of Creativity, with Special Attention to the Use of Digital Tools in Architectural Work. Revista Comunicação e Sociedade, Braga, Portugal, v. 22. 2012. Disponível em: 〈http://goo.gl/ZTqDzW〉. Acesso em: jan. 2015.

TAKAHASHI, Tadao (Org). Sociedade da informação no Brasil - Livro Verde. Brasília: MCT. set. 2000.

\section{Como citar este documento:}

ABEGG, Ilse; DE BASTOS, Fábio da Purificação. Convergência e integração de tecnologias criativas em ambientes virtuais. ETD - Educação Temática Digital, Campinas, SP, v. 18, n. 1, p. 60-70, abr. 2016. ISSN 1676-2592.

Disponível em: <http://periodicos.sbu.unicamp.br/ojs/index.php/etd/article/view/8635592>. Acesso em: 05 abr. 2016. doi: 〈http://dx.doi.org/10.20396/etd.v18i1.8635592>. 